\title{
Nocardioides furvisabuli sp. nov., isolated from black sand
}

\author{
Soon Dong Lee
}

Correspondence

Soon Dong Lee

sdlee@cheju.ac.kr
The genera Nocardioides and Marmoricola are characterized chemotaxonomically within the family Nocardioidaceae by the combination of LL-diaminopimelic acid in the peptidoglycan and the presence of respiratory quinone MK$8\left(\mathrm{H}_{4}\right)$ as the major menaquinone (O'Donnell et al., 1982; Prauser, 1976; Urzì et al., 2000). These genera are phylogenetically intermixed within the radiation of the family Nocardioidaceae but can be readily differentiated from each other on the basis of cell morphology and the cellular fatty acid profile (Urzì et al., 2000).

Since the original description by Prauser (1976), the number of Nocardioides species described has increased rapidly because of improved classification resulting from the polyphasic approach. Currently, there are 17 species (isolated mainly from terrestrial and aquatic substrates) with validly published names. Of these, Nocardioides ganghwensis (Yi \& Chun, 2004a) and Nocardioides aestuarii (Yi \& Chun, 2004b) were isolated recently from tidal flat sediments.

The GenBank/EMBL/DDBJ accession number for the 16S rRNA gene sequence of strain SBS-26 ${ }^{\top}$ is DQ411542.

The cellular fatty acid compositions of strain SBS- $26^{\top}$ growing on different media are presented in a supplementary table available in IJSEM Online.
Strain SBS- $26^{\mathrm{T}}$ was isolated from samples of black sand collected around Samyang Beach on Jeju Island, Republic of Korea, and its taxonomic status was investigated by using a polyphasic approach. For bacterial isolation, a sand sample $(1 \mathrm{~g})$ was placed into a sterile tube containing $9 \mathrm{ml}$ sterile seawater. After mixing for $30 \mathrm{~min}$ on a tube rotator, aliquots $(100 \mu \mathrm{l})$ of the serial diluents of the samples were transferred directly onto ISP 4 medium (Shirling \& Gottlieb, 1966) supplemented with $60 \%(\mathrm{v} / \mathrm{v})$ natural seawater. The agar plates were incubated at $30^{\circ} \mathrm{C}$ for 14 days and the isolate was subcultured on ISP 2 medium (Shirling \& Gottlieb, 1966) supplemented with $60 \%(\mathrm{v} / \mathrm{v})$ natural seawater (YE/SW agar). The pure culture was maintained at -20 and $-80^{\circ} \mathrm{C}$ in a $20 \%(\mathrm{v} / \mathrm{v})$ glycerol suspension supplemented with $60 \%$ $(\mathrm{v} / \mathrm{v})$ natural seawater.

The extraction of chromosomal DNA, the amplification and purification of the 16S rRNA gene by PCR and the direct sequencing of the purified PCR product were performed as described previously (Lee et al., 2000; Lee, 2006). The almost-complete sequence (1392 nt) of the 16S rRNA gene of strain SBS- $26^{\mathrm{T}}$ determined in this study was compared, using the CLUSTAL X program (Thompson et al., 1997), with those of representatives of the family Nocardioidaceae. The aligned sequences were manually adjusted according to the secondary structure of the Escherichia coli 16S rRNA gene 
sequence (Brosius et al., 1978). Phylogenetic analyses were carried out using the neighbour-joining (Saitou \& Nei 1987), maximum-parsimony (Fitch, 1971) and maximumlikelihood (Felsenstein, 1981) methods. The neighbourjoining tree was constructed with a distance matrix calculated using the method described by Jukes \& Cantor (1969). Streptomyces griseus KCTC $9080^{\mathrm{T}}$ (GenBank accession no. M76388) was used as an outgroup organism. The stability of the tree topology was evaluated by bootstrap analysis (Felsenstein, 1985). The neighbour-joining tree (Fig. 1) based on the comparison of $16 \mathrm{~S}$ rRNA gene sequences revealed that the organism is related to, but distinct from, members of the genera Nocardioides and Marmoricola of the family Nocardioidaceae and formed a distinct clade at the foot of the N. ganghwensis-N. oleivorans cluster, with a high level of bootstrap support (100\%). This branching pattern of the isolate was also found in the trees obtained using the maximum-parsimony and maximumlikelihood treeing algorithms. The $16 \mathrm{~S}$ rRNA gene sequence of strain SBS- $26^{\mathrm{T}}$ showed the highest levels of similarity with those of N. ganghwensis JC2055 ${ }^{\mathrm{T}}(97.7 \%)$ and Nocardioides oleivorans DSM $16090^{\mathrm{T}}(97.6 \%)$. The levels of $16 \mathrm{~S}$ rRNA gene sequence similarity between strain SBS- $26^{\mathrm{T}}$ and other members of the genera Nocardioides and members of the genus Marmoricola were in the range 93.0-96.2\%.

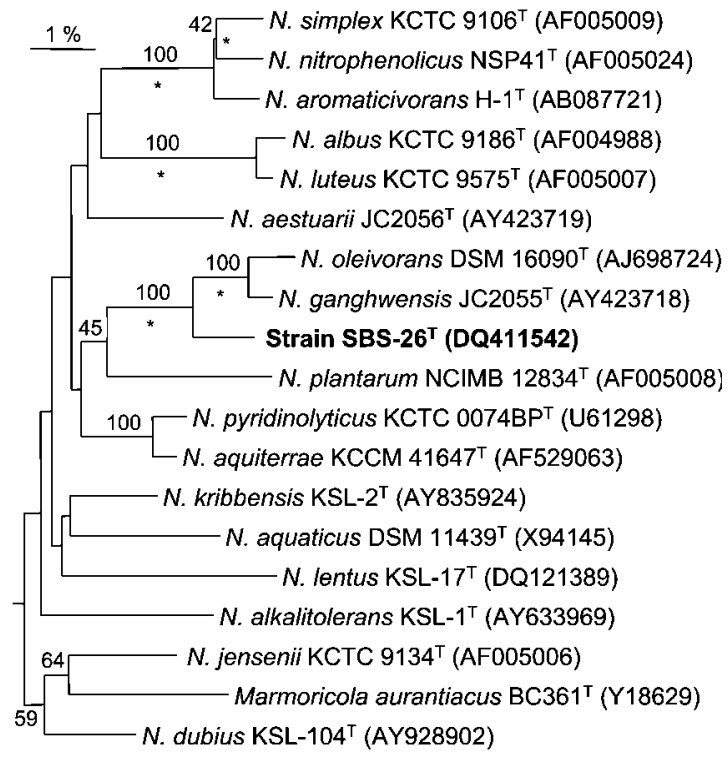

Fig. 1. Neighbour-joining phylogenetic tree showing the relationships between strain SBS- $26^{\top}$ and members of the genera Marmoricola and Nocardioides, based on 16S rRNA gene sequences. Asterisks indicate that the corresponding branch is also recovered in the maximum-likelihood and maximum-parsimony trees. Levels of bootstrap support, expressed as percentages of 1000 resampled datasets from a neighbour-joining analysis, are given at nodes if greater than $40 \%$. Bar, 1 nucleotide substitution per 100 nucleotides.
Growth on various culture media was tested by using ISP 2 medium (Shirling \& Gottlieb, 1966), trypticase soy broth agar (TSBA; Difco) and nutrient agar (NA; Difco) and marine agar (MA; Difco). To test the requirement for seawater, culture media (with the exception of MA) were each supplemented with $60 \%(\mathrm{v} / \mathrm{v})$ natural seawater. The degree of growth was recorded after incubation for 7 days at $30{ }^{\circ} \mathrm{C}$. The growth temperature and $\mathrm{pH}$ were tested at $4-45^{\circ} \mathrm{C}$ and $\mathrm{pH} 4.1-12.1$. $\mathrm{NaCl}$ tolerance during growth was determined in ISP 2 medium supplemented with 0-9, 10 and $15 \%(\mathrm{w} / \mathrm{v}) \mathrm{NaCl}$. Cell morphology and motility were investigated under phase-contrast and transmission electron microscopy, using 3-day-old cultures. Colony pigmentation was observed visually and recorded using 5-day-old cultures growing on $\mathrm{YE} / \mathrm{SW}$ agar at $30^{\circ} \mathrm{C}$. Carbohydrate utilization was tested using ISP 9 medium (Shirling \& Gottlieb, 1966): each filter-sterilized carbon source was tested at a final concentration of $1 \%(\mathrm{w} / \mathrm{v})$ (for carbohydrates and alcohols) or $0.1 \%(\mathrm{w} / \mathrm{v})$ (for organic acids). The Gram reaction was determined by using a Gram-stain kit (bioMérieux) according to the instructions of the manufacturer. Oxidase activity was tested by assessing the oxidation of $1 \% \quad(\mathrm{w} / \mathrm{v}) \quad N, N, N^{\prime}, N^{\prime}$-tetramethyl-p-phenylenediamine. Catalase activity was determined with a $3 \%(\mathrm{v} / \mathrm{v}) \mathrm{H}_{2} \mathrm{O}_{2}$ solution. The decomposition of hypoxanthine, DL-tyrosine and xanthine was determined as described previously (Gordon et al., 1974). The degradation of elastin was investigated on ISP 2 medium supplemented with $0.3 \%(\mathrm{w} / \mathrm{v})$ elastin. The hydrolysis of aesculin, casein and starch was assessed using the methods of MacFaddin (1980). Other physiological and biochemical properties were tested with the API 20E, API 20NE and API ZYM systems (bioMérieux). For phenotypic comparisons, N. ganghwensis IMSNU $14028^{\mathrm{T}}$ and $N$. oleivorans DSM $16090^{\mathrm{T}}$ were used as reference strains and further investigated for physiological and biochemical properties not previously tested (Yi \& Chun, 2004a; Schippers et al., 2005).

Strain SBS-26 ${ }^{\mathrm{T}}$ showed good growth on ISP 2 medium, NA and MA. No growth occurred on TSBA irrespective of supplementation with natural seawater, whereas the reference strains, $N$. ganghwensis IMSNU $14028^{\mathrm{T}}$ and $N$. oleivorans DSM $16090^{\mathrm{T}}$, showed good growth on TSBA. The cells of strain SBS- $26^{\mathrm{T}}$ were motile (flagellated) short rods $(0.4-0.5 \times 0.6-1.2 \mu \mathrm{m})$ but did not produce mycelium or spores (Fig. 2). On YE/SW agar, the colonies were circular, smooth, convex and yellow in colour. After incubation for 5 days, the colonies reached a diameter of $0.6-0.8 \mathrm{~mm}$. The physiological and biochemical characteristics of strain SBS$26^{\mathrm{T}}$ are given in the species description and are compared with those of $N$. ganghwensis and N. oleivorans in Table 1.

Biomass for the chemotaxonomic characterization was obtained from 3-day-old cultures growing on YE/SW broth at $30{ }^{\circ} \mathrm{C}$. The isomer type of the cell-wall diaminopimelic acid was analysed as described previously (Staneck \& Roberts, 1974). Isoprenoid quinones were extracted as described by Minnikin et al. (1984) and analysed using the 


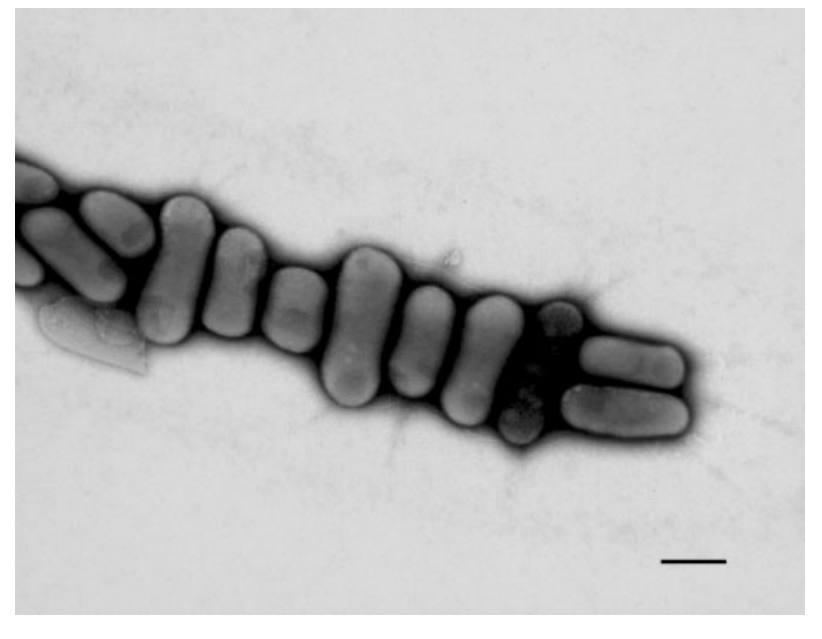

Fig. 2. Transmission electron micrograph of cells of strain SBS$26^{\top}$ grown on YE/SW agar for 3 days at $30^{\circ} \mathrm{C}$. Bar, $500 \mathrm{~nm}$.

method described by Kroppenstedt (1985). Polar lipids were separated using $6.6 \times 6.6 \mathrm{~cm}$ TLC silica gel $60 \mathrm{~F}_{254}$ plates (Merck) according to the method described by Minnikin et al. (1977). Individual phospholipids were identified by using several spray reagents (Embley \& Wait, 1994) and through co-migration with authentic standards (Sigma). To determine the cellular fatty acid composition, cells were cultivated on YE/SW agar and MA at $30^{\circ} \mathrm{C}$ for 5 days. Fatty acid methyl esters were prepared and analysed according to the instructions of the Microbial Identification System (MIDI). The $\mathrm{G}+\mathrm{C}$ content of the DNA was determined by using HPLC with a Supelcosil LC-18-S $(150 \times 4.6 \mathrm{~mm})$ column, as described by Mesbah et al. (1989). Strain SBS$26^{\mathrm{T}}$ contained LL-type diaminopimelic acid as the diagnostic cell-wall diamino acid. MK-8 $\left(\mathrm{H}_{4}\right)$ was the predominant menaquinone. The DNA $\mathrm{G}+\mathrm{C}$ content, determined by HPLC, was $69.1 \mathrm{~mol} \%$. Most of the chemotaxonomic features of strain SBS- $26^{\mathrm{T}}$ were consistent with those of the genus Nocardioides (Collins et al., 1994; Lawson et al., 2000; O'Donnell et al., 1982; Schippers et al., 2005; Yi \& Chun, 2004a, b; Yoon et al., 1997, 1999, 2004, 2005, 2006). Strain SBS- $26^{\mathrm{T}}$ had a cellular fatty acid profile characterized by the presence of large amounts of straight-chain, branched and unsaturated fatty acids, and a major amount of iso- $\mathrm{C}_{16: 0}$ irrespective of the culture medium used (see Supplementary Table S1 available in IJSEM Online). In general, cellular fatty acid compositions can vary according to the culture medium and growth conditions used (Kroppenstedt, 1985); under the conditions used in our study, the other major fatty acid was $\mathrm{C}_{18: 1} \omega 9 c$ (YE/SW agar) but, on MA, $\mathrm{C}_{18: 0}$ and $\mathrm{C}_{16: 0}$ were also detected as principal components. The polar lipids comprised phosphatidylcholine, phosphatidylglycerol, phosphatidylinositol and an unknown phospholipid. The presence of phosphatidylcholine in the phospholipid profile can serve as a key marker for differentiating the novel isolate from members of the genus Nocardioides (O'Donnell et al., 1982).

The phylogeny based on 16S rRNA gene sequences suggested that the isolate belonged to the genus Nocardioides; however, the strain consistently formed a distinct clade at the base of the N. ganghwensis-N. oleivorans cluster (Fig. 1), indicating that the organism could be a novel member of the genus. This relationship is clear in that a number of phenotypic characteristics sharply distinguish between the isolate and its phylogenetic relatives (Table 1), as do chemotaxonomic markers such as the phospholipid and fatty acid compositions. On the basis of the combination of the physiological and chemotaxonomic features and its phylogenetic distinctness, strain SBS- $26^{\mathrm{T}}$ represents a novel species of the genus Nocardioides, for which the name Nocardioides furvisabuli sp. nov. is proposed.

\section{Description of Nocardioides furvisabuli sp. nov.}

Nocardioides furvisabuli (fur.vi.sa'bu.li. L. neut. adj. furvum black-coloured; L. neut. n. sabulum gravel, sand; N.L. gen. n. furvisabuli of black-coloured sand, the source of isolation of the type strain).

Gram-positive, aerobic, oxidase-negative, catalase-positive. Cells are motile, short rods $(0.4-0.5 \times 0.6-1.2 \mu \mathrm{m})$. Colonies are circular, smooth, convex, yellow in colour and $0.6-0.8 \mathrm{~mm}$ in diameter after 5 days incubation on YE/ $\mathrm{SW}$ agar at $30^{\circ} \mathrm{C}$. The temperature range for growth is $4-37^{\circ} \mathrm{C}$, with optimum growth at $30^{\circ} \mathrm{C}$. The $\mathrm{pH}$ range for growth is $\mathrm{pH}$ 5.1-10.1, with optimum growth at $\mathrm{pH}$ 7.1. Growth occurs in the presence of $0-6 \% \mathrm{NaCl}$. Good growth occurs on ISP 2, NA (with/without the addition of natural seawater) and marine agar. Growth does not occur on TSBA medium. Nitrate is reduced to nitrite. $\mathrm{H}_{2} \mathrm{~S}$ and indole production are not detected. Urease activity is not detected. Voges-Proskauer reaction is weakly positive. Casein and starch are hydrolysed but gelatin is not hydrolysed. Elastin is degraded. Decomposition of hypoxanthine, DL-tyrosine or xanthine does not occur. Acid is not produced from glucose. Positive for esterase lipase (C8). Weakly positive for valine arylamidase and $\alpha$-galactosidase. Negative for lysine decarboxylase, ornithine decarboxylase, tryptophan deaminase, esterase (C4), cystine arylamidase and acid phosphatase. LArabinose, inulin, methyl $\alpha$-D-mannoside, D-raffinose, Dxylose, adonitol, D-dulcitol, glycerol and D-mannitol are utilized as sole carbon and energy sources. D-Arabinose, dextran, D-melezitose, methyl $\alpha$-D-glucoside, sucrose, Lrhamnose, salicin, L-sorbose, 2,3-butanediol, meso-erythritol and D-xylitol are not utilized. Assimilation of citrate, formate, malate, succinate and tartrate is observed. Weakly positive for the assimilation of acetate and the utilization of myo-inositol, 1,2-propanediol and D-sorbitol. The predominant fatty acids are iso- $\mathrm{C}_{16: 0}$ and $\mathrm{C}_{18: 1} \omega 9 c$ (on YE/SW agar) or iso- $\mathrm{C}_{16: 0}, \mathrm{C}_{18: 0}$ and $\mathrm{C}_{16: 0}$ (on MA). Polar lipids contain phosphatidylcholine, phosphatidylglycerol, phosphatidylinositol and an unknown phospholipid. The DNA 
Table 1. Characteristics that differentiate strain SBS $-26^{\top}$ from phylogenetic relatives from the genus Nocardioides

Strains: 1, SBS- $26^{\mathrm{T}} ; 2$, N. ganghwensis IMSNU $14028^{\mathrm{T}} ; 3$, N. oleivorans DSM $16090^{\mathrm{T}}$. Data were taken from Yi \& Chun (2004a), Schippers et al. (2005) and this study. Symbols: +, positive; -, negative; $\mathrm{W}$, weakly positive; $\mathrm{V}$, variable. All strains are positive for the Gram reaction, catalase and $\beta$-galactosidase and negative for arginine dihydrolase, glucose fermentation, indole production from tryptophan and urease (API 20NE kit). Casein and DNA are degraded by all strains but cellulose or hypoxanthine are not. Alkaline phosphatase and leucine arylamidase are positive for all of the strains, but lipase (C14), trypsin, $\alpha$-chymotrypsin, naphtholAS-BI-phosphohydrolase, $\beta$-glucuronidase, $\beta$-glucosidase, $N$-acetyl$\beta$-glucosamidase, $\alpha$-mannosidase or $\alpha$-fucosidase are negative (API ZYM kit). All strains utilize D-cellobiose, D-fructose, D-galactose, D-glucose, D-lactose, maltose, D-mannitol, D-mannose and D-trehalose but not benzoate or D-ribose.

\begin{tabular}{|c|c|c|c|}
\hline Characteristic & 1 & 2 & 3 \\
\hline Motility & + & - & - \\
\hline $\mathrm{NaCl}$ tolerance for growth (\%) & $0-6$ & $0-8$ & $0-2$ \\
\hline Nitrate reduction & + & + & - \\
\hline \multicolumn{4}{|l|}{ Hydrolysis of: } \\
\hline Aesculin & - & $\mathrm{W}$ & + \\
\hline Gelatin & - & + & - \\
\hline Starch & + & + & - \\
\hline Tween 80 & - & + & - \\
\hline \multicolumn{4}{|l|}{ Degradation of: } \\
\hline Tyrosine & - & + & - \\
\hline Xanthine & - & $\mathrm{W}$ & - \\
\hline \multicolumn{4}{|l|}{ API ZYM tests } \\
\hline Esterase (C4) & - & $\mathrm{V}$ & $\mathrm{W}$ \\
\hline Esterase lipase (C8) & + & + & $\mathrm{W}$ \\
\hline Valine arylamidase & $\mathrm{w}$ & + & + \\
\hline Cystine arylamidase & - & $\mathrm{W}$ & $\mathrm{W}$ \\
\hline Acid phosphatase & - & $\mathrm{w}$ & - \\
\hline$\alpha$-Galactosidase & $\mathrm{w}$ & + & - \\
\hline$\alpha$-Glucosidase & - & + & + \\
\hline \multicolumn{4}{|l|}{ Utilization of carbon sources } \\
\hline Acetate & $\mathrm{w}$ & + & + \\
\hline Adonitol & + & - & - \\
\hline L-Arabinose & + & + & - \\
\hline Citrate & + & + & - \\
\hline Formate & + & - & - \\
\hline Glycerol & + & + & - \\
\hline Inositol & w & - & - \\
\hline Inulin & + & - & - \\
\hline Malate & + & - & + \\
\hline Melibiose & - & + & + \\
\hline D-Raffinose & + & + & - \\
\hline L-Rhamnose & - & + & + \\
\hline D-Salicin & - & + & - \\
\hline D-Sorbitol & $\mathrm{w}$ & - & - \\
\hline Sucrose & - & + & + \\
\hline D-Xylose & + & + & - \\
\hline Acid production from D-glucose & - & - & + \\
\hline
\end{tabular}

$\mathrm{G}+\mathrm{C}$ content is $69.1 \mathrm{~mol} \%$. Other characteristics are given in Table 1.

The type strain, SBS-26 ${ }^{\mathrm{T}} \quad\left(=\mathrm{JCM} \quad 13813^{\mathrm{T}}=\mathrm{NRRL} \quad \mathrm{B}-\right.$ $24465^{\mathrm{T}}$ ), was isolated from black sand from Samyang Beach on Jeju Island, Republic of Korea.

\section{Acknowledgements}

We thank Professor J. Chun (IMSNU) and Dr R. Pukall (DSMZ) for providing the type strains of $N$. ganghwensis and $N$. oleivorans, respectively. This work was supported by the 21C Frontier Microbial Genomics and Application Center Program, Ministry of Science and Technology, Republic of Korea. The author is indebted to H. L. Yang and U.-G. Kim for technical assistance.

\section{References}

Brosius, J., Palmer, M. L., Kennedy, J. P. \& Noller, H. F. (1978). Complete nucleotide sequence of a $16 \mathrm{~S}$ ribosomal RNA gene from Escherichia coli. Proc Natl Acad Sci U S A 75, 4801-4805.

Collins, M. D., Cockcroft, S. \& Wallbanks, S. (1994). Phylogenetic analysis of a new LL-diaminopimelic acid-containing coryneform bacterium from herbage, Nocardioides plantarum sp. nov. Int J Syst Bacteriol 44, 523-526.

Embley, T. M. \& Wait, R. (1994). Structural lipids of eubacteria. In Chemical Methods in Prokaryotic Systematics, pp. 121-161. Edited by M. Goodfellow \& O'Donnell. Chichester: Wiley.

Felsenstein, J. (1981). Evolutionary trees from DNA sequences: a maximum likelihood approach. J Mol Evol 17, 368-376.

Felsenstein, J. (1985). Confidence limits on phylogenies: an approach using the bootstrap. Evolution 39, 783-791.

Fitch, W. M. (1971). Toward defining the course of evolution: minimum change for a specific tree topology. Syst Zool 20, 406-416.

Gordon, R. E., Barnett, D. A., Handerhan, J. E. \& Pang, C. H.-N. (1974). Nocardia coeliaca, Nocardia autotrophica, and the nocardin strain. Int J Syst Bacteriol 24, 54-63.

Jukes, T. H. \& Cantor, C. R. (1969). Evolution of protein molecules. In Mammalian Protein Metabolism, pp. 21-132. Edited by $\mathrm{H}$. N. Munro. New York: Academic Press.

Kroppenstedt, R. M. (1985). Fatty acid and menaquinone analysis of actinomycetes and related organisms. In Chemical Methods in Bacterial Systematics, pp. 173-199. Edited by M. Goodfellow \& D. E. Minnikin. London: Academic Press.

Lawson, P. A., Collins, M. D., Schumann, P., Tindall, B. J., Hirsch, P. \& Labrenz, M. (2000). New LL-diaminopimelic acid-containing actinomycetes from hypersaline, heliothermal and meromictic Antarctic Ekho Lake: Nocardioides aquaticus sp. nov. and Friedmanniella lacustris sp. nov. Syst Appl Microbiol 23, 219-229.

Lee, S. D. (2006). Nocardia jejuensis sp. nov., a novel actinomycete isolated from a natural cave on Jeju Island, Republic of Korea. Int J Syst Evol Microbiol 56, 559-562.

Lee, S. D., Kang, S.-O. \& Hah, Y. C. (2000). Hongia gen. nov., a new genus of the order Actinomycetales. Int J Syst Evol Microbiol 50, 191-199.

MacFaddin, J. F. (1980). Biochemical Tests for Identification of Medical Bacteria, 2nd edn. Baltimore: Williams \& Wilkins.

Mesbah, M., Premachandran, U. \& Whitman, W. B. (1989). Precise measurement of the $\mathrm{G}+\mathrm{C}$ content of deoxyribonucleic acid by highperformance liquid chromatography. Int J Syst Bacteriol 39, 159-167. 
Minnikin, D. E., Alshamaony, L. \& Goodfellow, M. (1977). Differentiation of Mycobacterium, Nocardia, and related taxa by thin layer chromatographic analysis of whole-cell methanolysates. J Gen Microbiol 88, 200-204.

Minnikin, D. E., O’Donnell, A. G., Goodfellow, M., Alderson, G., Athalye, M., Schaal, A. \& Parlett, J. H. (1984). An integrated procedure for the extraction of bacterial isoprenoid quinones and polar lipids. J Microbiol Methods 2, 233-241.

O'Donnell, A. G., Goodfellow, M. \& Minnikin, D. E. (1982). Lipids in the classification of Nocardioides: reclassification of Arthrobacter simplex (Jensen) Lochhead in the genus Nocardioides (Prauser) emend. O'Donnell et al. as Nocardioides simplex comb. nov. Arch Microbiol 133, 323-329.

Prauser, H. (1976). Nocardioides, a new genus of the order Actinomycetales. Int J Syst Bacteriol 26, 58-65.

Saitou, N. \& Nei, M. (1987). The neighbor-joining method: a new method for reconstructing phylogenetic trees. Mol Biol Evol 4, 406-425.

Schippers, A., Schumann, P. \& Spröer, C. (2005). Nocardioides oleivorans sp. nov., a novel crude-oil-degrading bacterium. Int J Syst Evol Microbiol 55, 1501-1504.

Shirling, E. B. \& Gottlieb, D. (1966). Methods for characterization of Streptomyces species. Int J Syst Bacteriol 16, 313-340.

Staneck, J. L. \& Roberts, G. D. (1974). Simplified approach to identification of aerobic actinomycetes by thin-layer chromatography. Appl Microbiol 28, 226-231.
Thompson, J. D., Gibson, T. J., Plewniak, F., Jeanmougin, F. \& Higgins, D. G. (1997). The CLUSTAL_X windows interface: flexible strategies for multiple sequence alignment aided by quality analysis tools. Nucleic Acids Res 25, 4876-4882.

Urzi, C., Salamone, P., Schumann, P. \& Stackebrandt, E. (2000). Marmoricola aurantiacus gen. nov., sp. nov., a coccoid member of the family Nocardioidaceae isolated from a marble statue. Int J Syst Evol Microbiol 50, 529-536.

Yi, H. \& Chun, J. (2004a). Nocardioides ganghwensis sp. nov., isolated from tidal flat sediment. Int J Syst Evol Microbiol 54, 1295-1299.

Yi, H. \& Chun, J. (2004b). Nocardioides aestuarii sp. nov., isolated from tidal flat sediment. Int J Syst Evol Microbiol 54, 2151-2154.

Yoon, J. H., Rhee, S.-K., Lee, J.-S., Park, Y.-H. \& Lee, S. T. (1997). Nocardioides pyridinolyticus sp. nov., a pyridine-degrading bacterium isolated from the oxic zone of an oil shale column. Int J Syst Bacteriol 47, 933-938.

Yoon, J.-H., Cho, Y. G., Lee, S. T., Suzuki, K., Nakase, T. \& Park, Y.-H. (1999). Nocardioides nitrophenolicus sp. nov., a p-nitrophenoldegrading bacterium. Int J Syst Bacteriol 49, 675-680.

Yoon, J.-H., Kim, I.-G., Kang, K. H., Oh, T.-K. \& Park, Y.-H. (2004). Nocardioides aquiterrae sp. nov., isolated from groundwater in Korea. Int J Syst Evol Microbiol 54, 71-75.

Yoon, J.-H., Lee, C.-H. \& Oh, T.-K. (2005). Nocardioides dubius sp. nov., isolated from an alkaline soil. Int J Syst Evol Microbiol 55, 2209-2212.

Yoon, J.-H., Lee, C.-H. \& Oh, T.-K. (2006). Nocardioides lentus sp. nov., isolated from an alkaline soil. Int J Syst Evol Microbiol 56, 271-275. 